\title{
Maternal Depressive Symptoms and Child Social Preference During the Early School Years: Mediation by Maternal Warmth and Child Emotion Regulation
}

\author{
Chi-Ming Kam • Mark T. Greenberg • \\ Karen L. Bierman • John D. Coie • Kenneth A. Dodge • \\ Michael E. Foster • John E. Lochman • \\ Robert J. McMahon • Ellen E. Pinderhughes • \\ Conduct Problems Prevention Research Group
}

Published online: 17 November 2010

(C) The Author(s) 2010. This article is published with open access at Springerlink.com

\begin{abstract}
This longitudinal study examined processes that mediate the association between maternal depressive symptoms and peer social preference during the early school years. Three hundred and fifty six kindergarten children (182 boys) and their mothers participated in the study. During kindergarten, mothers reported their level of depressive symptomatology. In first grade, teachers rated children's emotion regulation at school and observers rated
\end{abstract}

This work was supported by National Institute of Mental Health grants R18MH48083, R18MH50951, R18MH50952, and R18MH50953.

The Center for Substance Abuse Prevention, Department of

Education, and National Institute for Drug Abuse also provided support to Fast Track through a memorandum of support with the NIMH. Support has also come from the Department of Education grant S184430002 and NIMH grants K05MH00797 and $\mathrm{K} 05 \mathrm{MH} 01027$. Appreciation is expressed to the parents, teachers, students and school district personnel who supported this research in the Durham, Nashville, central Pennsylvania, and Seattle area.

C.-M. Kam $(\bowtie)$

Department of Psychology, University of Hong Kong,

Pokfulam Road,

Pokfulam, Hong Kong

e-mail: cmkam@hkucc.hku.hk

\section{T. Greenberg}

Prevention Research Center for Promotion of Human

Development, College of Health and Human Development,

Pennsylvania State University,

University Park, PA, USA

\section{K. L. Bierman}

Department of Psychology, Pennsylvania State University, University Park, PA, USA

J. D. Coie - K. A. Dodge

Duke University,

Durham, NC, USA the affective quality of mother-child interactions. During second grade, children's social preference was assessed by peer nomination. Results indicated that mothers' level of depressive symptomatology negatively predicted their child's social preference 2 years later, controlling for the family SES and teacher-rated social preference during kindergarten. Among European American families, the association between maternal depressive symptoms and
M. E. Foster

University of North Carolina,

Chapel Hill, NC, USA

\section{J. E. Lochman}

University of Alabama,

Tuscaloosa, AL, USA

R. J. McMahon

University of Washighton,

Seattle, WA, USA

E. E. Pinderhughes

Tufts University,

Medford/Somerville, MA, USA 
social preference was partially mediated by maternal warmth and the child's emotion regulation. Although the relation between maternal depressive symptoms and children peer preference was stronger among African American families than Europrean American families, its mediation by the maternal warmth and child's emotion regulation was not found in African American families.

Keywords Maternal Depressive Symptoms · Emotional Competence · Peer Relations · Parent-Child Interactional Style $\cdot$ Mediation

Two decades of research have documented a heightened risk of developing maladjustment and psychopathology among offspring of depressed mothers and mothers who experience high levels of depressive symptoms (see reviews by Downey and Coyne 1990; Goodman 2007; Goodman and Gotlib 1999). For instance, school-age children of mothers with a high level of depressive symptoms are more likely than their peers to experience emotional distress, depression, and anxiety (Gladstone and Kaslow 1995), as well as higher rates of conduct problems (Luoma et al. 2001; Weissman et al. 1984).

Women living in poverty are more likely to experience more symptoms of depression than women living in more affluent circumstances, particularly mothers with young children who are exposed to multiple stressors, such as violence and poor living conditions (Hwa-Froelich et al. 2008). In addition to the impact of poverty and its associated stressors on child development, maternal depressive symptoms make unique contributions, increasing child risk for developmental difficulties (Petterson and Albers 2001). Although much of the research on the deleterious effects of maternal depression has focused on clinic populations, depressive symptomatology may impact child development even at sub-clinical levels, particularly among vulnerable children who have limited access to support systems that might buffer the impact of maternal distress (Waylen and Stewart-Brown 2010).

Among children living in stressful circumstances, maternal depressive symptoms may provoke a negative developmental cascade, reducing the availability of maternal warmth and support in parent-child interactions, thereby weakening support for the child's developing emotion and stress regulation capacities. Poor emotion regulation, in turn, may alienate peers, reducing the child's capacity to elicit social support in the peer context. The present study tested this negative cascade model in a large sample of children living in high-risk neighborhoods. We predicted that, controlling for family SES, maternal depressive symptoms would contribute over time to reduced maternal warmth and availability in parent-child interactions and impair the development of child emotion regulation skills, which in turn, would mediate the negative effects of maternal depressive symptomatology on social preference among peers.

\section{Links Between Maternal Depressive Symptoms and Poor Peer Relations}

Several studies have documented links between maternal depressive symptoms and peer difficulties. For example, maternal depression during infancy predicted poor social functioning among a group of 5- to 8-year-old children, as rated by teachers (Wright et al. 2000). In another study, teachers rated children of depressed parents as more aggressive and less socially competent than their classmates, and peers viewed them as abrasive, withdrawn, and unhappy (Emery et al. 1982). Cummings et al. (2005) found that kindergarten children of mothers who experienced high levels of depressive symptoms were more often excluded by peers than other children. Teachers judged elementary school-age children of depressed mothers to have low popularity (Goodman et al. 1993).

There are a number of mechanisms that might account for the links between maternal depressive symptoms and impairments in child social competence and peer relations (Blandon et al. 2008; Zahn-Waxler et al. 1992). First, symptoms of depression, such as dysphoria, apathy, and mood swings, could reduce the frequency, predictability, positive valence, and quality of mother-child interactions, thereby reducing support for the child's social-emotional development. Second, mother's mood disturbance could reduce her capacity to serve as a secure base and source of emotional support for the child, reducing the child's emotion regulation skills and isolating the child from the kind of social support that might buffer the child from the stressful living circumstances of the family. Third, there is the possibility of genetic linkages involving the biological transmission of negative emotionality and vulnerability to depression from mother to child. Evidence supporting the hypothesis that maternal depression and associated symptoms negatively affect child peer relations via reductions in the quality of the mother-child relationship and via reductions in child emotion regulation skills are discussed in the next sections.

\section{Links between Maternal Depressive Symptoms, Mother-Child Interaction Quality, and Peer Relations}

Researchers studying the "family-peer link" suggest that active parental involvement in and support for child social interactions play a key role in promoting the development of social-emotional competence and positive peer relations. 
In their tripartite model, Parke and colleagues (Parke et al. 1994) propose that parents promote positive peer relations by: 1) engaging in positive, warm, and sensitive interactions with their children, 2) providing suggestions and instructions to support prosocial behavior and teach effective emotion regulation and conflict management skills, and 3) arranging and supervising play opportunities. Consistent with this model, research has shown that the affective quality of parent-child interactions is related to the child's peer competence. Parents who interact with their children in warm, sensitive and responsive ways are more likely to have children who exhibit prosocial behavior and are accepted by their peers than are parents who are uninvolved or critical and harsh (Gottman and Katz 1989; Hart et al. 1990). Compared to mothers of children with high sociometric status, mothers of first grade children with low social status were less positive, less focused on feelings, and more disagreeable and demanding when interacting with their children, modeling less competent social interaction strategies (Putallaz 1987; Putallaz and Heflin 1990).

Research suggests that maternal depression and associated symptoms may reduce the quality of parent-child interactions, contributing to less warm, less available, and less sensitive parenting during daily interactions, and thereby reducing support for the development of child social competencies and peer interaction skills. Specifically, mothers with high rates of depressive symptoms are characterized by low sociability and responsiveness, and difficulty initiating and sustaining social interaction (Field et al. 1990; Hwa-Froelich et al. 2008; Lovejoy et al. 2000). Depressed mothers are also more hostile, intrusive, harsh and critical than nondepressed mothers in their interactions with their young children (Caughy et al. 2009; Huang et al. 2007; Webster-Stratton and Hammond 1988). In this study focused on school aged children, we hypothesize that the impact of maternal depressive symptomatology on child social preference is mediated by the quality of mother-child interactions, particularly the emotional availability, warmth, and sensitive-responding of the parent to child.

\section{Links Between Maternal Depressive Symptoms, Child Emotion Regulation, and Peer Relations}

Although researchers have long recognized the relations between children's emotional competence and peer social preference (e.g. Cillessen and Mayeux 2004; Contreras and Kerns 2000; Gottman et al. 1996), it is only recently that integrated theoretical models have been articulated in which the child's ability to regulate emotional arousal is identified as a key factor influencing the child's social behavior and peer social preference. For example, in their adapted Social Information Processing model, Lemerise and Arsenio
(2000) suggest that emotions related to children's peer relations interact with the child's social cognitive processes, and permeate each step of the social information processing (SIP) process during peer interactions (Crick and Dodge 1994; Lemerise and Arsenio 2000). In support of this model, Hubbard (2001) found that poorly regulated emotion expression was associated with peer rejection. Rejected children expressed more facial and verbal anger than average status children.

Denham and colleagues showed that emotional competence could be measured distinctly, and predicted preschoolers' social competence (Denham et al. 2003). Halberstadt et al. (2001) defined the construct of affective social competence (ASC) as "the efficacious communication of one's own affect, one's successful interpretation and response to others' affective communications, and the awareness, acceptance, and management of one's own affect" (p. 80). These studies, as well as others, established emotion regulation as an important developing skill associated with positive peer relations. In particular, Hubbard and Dearing (2004) demonstrated that emotion processes, including emotion understanding and emotion regulation, had an impact on the formation of peer impressions and preferences. Teacher ratings of boys' ability to cope constructively with negative emotions were positively related to the boys' social status, whereas teachers' ratings of boys' acting out in response to peer provocation were negatively related to their social status (Eisenberg et al. 1993). Children with poor emotional competence also are more likely to be actively disliked by peers, due possibly to their difficulties regulating anger, and corresponding higher rates of aggressive and disruptive behavior (Eisenberg et al. 2001; Hubbard and Coie 1994).

Parents are primary socializing agents of children's emotion regulation skills (Denham et al. 1997; Denham et al. 1994; Eisenberg et al. 1998; Spinrad et al. 2006). Denham et al. (1997, 1994) suggest that modeling, coaching, and contingency are the three major methods parents use to support their young child's ASC. Spinrad et al. (2006) suggest that parents influence child emotional development in the course of parent-child interactions, by the way in which they express emotions, discuss emotions, and react to child emotions. Mothers who are overwhelmed by their own emotional distress may not effectively support their child's emotional competence. They may instead behave in ways that escalate or provoke the child's emotional insecurity and dysregulation.

\section{Ethnic Differences in Risk Transmission}

While we expect the negative influence of maternal depressive symptomatology on children's social develop- 
ment to be universal, the literature on harsh parenting and physical discipline suggests that there might be ethnic differences in the transmission of risk in different ethnic groups. Specifically, Deater-Deckard and colleagues found that parents' use of moderate physical punishment predicted children's problem behaviors among European American but not African American families (Deater-Deckard et al. 2003; Dodge et al. 2005). Deater-Deckard et al. suggested that different kinds of risk transmission processes maybe involved in different ethnic groups. In light of such findings, we examined whether there are differences between African American and European American families in the way that maternal depressive symptoms confer risk to child peer relations.

\section{The Present Study}

This longitudinal study focused on the impact of maternal depressive symptoms on children's social and emotional adjustment during the early elementary school years, a period when children are starting to establish social reputations among their peers and when social competence and emotion regulation skills play an increasing role in children's school adjustment (Bierman 2004; Parker et al. 2006). We focused on families living in high-risk neighborhoods, where rates of maternal depressive symptomatology and child adjustment problems occur at heightened levels, and where the quality of mother-child interactions and child emotion regulation skills maybe of particular importance in promoting adaptation (Dodge et al. 2005). An understanding of how maternal depressive symptomatology influences children in high risk environments and socially disadvantaged sociocultural groups is particularly relevant to the design of prevention programs.

In this study, we tested a risk model in which we hypothesized that maternal depressive symptomatology would decrease children's peer social preference. Using 3 years of data, we further tested the extent to which the impact of maternal depressive symptoms was mediated by the affective quality of mother-child interactions and the child's emotion regulation skills. Additionally, we examined whether the pattern of mediation differed for African American and European American families. Responding to the call for independent data in maternal depression research (Burt et al. 2005), separate informants were used to assess the four constructs in the model maternal reports of their depressive symptomatology, observer ratings of the quality of mother-child interaction, teacher ratings of child emotion regulation, and peer nominations of child social preference.

\section{Method}

Participants

Participants represented a sub-sample of mothers and children participating in the Fast Track Project developmental study (Conduct Problems Prevention Research Group [CPPRG], 1992). Although the Fast Track Project included a preventive intervention, this study utilized the normative sample from the Fast Track study, which included children randomly selected from the control (non-intervention) schools. Recruitment targeted schools located in four study sites within the U.S.: 1) Durham, $\mathrm{NC}$, a small city with a large low- to middle-SES, primarily African-American population; 2) Nashville, $\mathrm{TN}$, a moderate-sized city with a mix of low- to middle-SES, African-American and European-American families; 3) Seattle, WA, a moderate-sized city with a low- to middle-SES, ethnically diverse population; and 4) Central Pennsylvania, a mostly rural area with low- to middle-SES, European-American families. The study was approved by the institutional review boards at each of the participating universities. Informed consent was obtained from parents for their own and their child's participation.

During the spring of kindergarten, all the children enrolled in the control schools were rated by their teachers for the presence of behavioral problems. Blocked to represent the ethnic, gender, and teacher-rating scores that characterized each site, normative samples of 100 children were randomly selected at each site (Lochman \& CPPRG, 1995). Across all sites, the sample mean age in Year 1 (i.e., when the children entered first grade) was 6.37 years $(\mathrm{SD}=0.45$ ), $51 \%$ of the children were boys, and $47 \%$ of the sample had a minority ethnic background (43\% African American and 4\% other). The actual size of the sample in the present study $(N=356)$ is a few cases less than that of the normative sample $(N=387)$, as some of the primary caretakers in the normative sample were fathers and these cases were deleted from this study. The Fast Track study drew its sample from schools that served high-risk and economically-disadvantaged neighborhoods and hence included a greater representation of students with problem behaviors and families burdened with multiple stressors (including maternal depression) than typically found in community studies using a broader sampling frame. Preliminary analyses of the demographic characteristics of the mother sample showed that a relatively high percentage of the mothers in the sample were single parents, poor, unmarried, and African American factors associated with increased risk for maternal depression (see Table 1). 
Table 1 Demographic characteristic of mothers in the study sample when children were in kindergarten $(N=356)$

\begin{tabular}{|c|c|c|}
\hline Maternal characteristics & Number & Percentage \\
\hline \multicolumn{3}{|l|}{ Race } \\
\hline European American & 194 & 54.49 \\
\hline African American & 143 & 40.17 \\
\hline Hispanic & 5 & 1.40 \\
\hline Others & 11 & 3.09 \\
\hline Not reported & 3 & 0.84 \\
\hline \multicolumn{3}{|l|}{ Age } \\
\hline Less than 25 & 40 & 11.24 \\
\hline $25-35$ & 257 & 72.19 \\
\hline $36-39$ & 41 & 11.52 \\
\hline 40 and above & 18 & 5.06 \\
\hline \multicolumn{3}{|c|}{ Socioeconomic status (Hollingshead scale) } \\
\hline $1-2$ & 69 & 19.38 \\
\hline $3-4$ & 169 & 47.47 \\
\hline 5 & 118 & 33.15 \\
\hline \multicolumn{3}{|l|}{ Years of education } \\
\hline$<10$ years & 32 & 8.99 \\
\hline $10-12$ years & 226 & 63.48 \\
\hline 13 to 17 years & 92 & 25.84 \\
\hline $18+$ years & 6 & 1.69 \\
\hline \multicolumn{3}{|l|}{ Marital status } \\
\hline Married & 177 & 49.72 \\
\hline Separated/Divorced & 68 & 19.10 \\
\hline Widowed & 2 & 0.56 \\
\hline Never Married & 81 & 22.75 \\
\hline Not Reported & 28 & 7.87 \\
\hline
\end{tabular}

\section{Measures}

Timing of Measurement Maternal depressive symptomatology, and the covariates of family SES and teacherrated peer preference were all assessed during children's kindergarten year. The quality of mother-child interaction was rated by observers and emotion regulation was assessed by teachers in the spring of first grade. Peer sociometric nominations were collected in the spring of second grade.

Maternal Depressive Symptoms The Center for Epidemiological Study of Depression Scale (CES-D) (Radloff 1977) has an emphasis on the affective component of depression, namely, depressed mood. Respondents are asked to rate the frequency, over the past week, of 20 symptoms rating each from "rarely or none of the time" to "most or all of the time". Scores range from 0 to 60 , with a score of 16 indicating impairment. The reliability and validity of the scale have been tested with clinic populations (Craig and
Van Natta 1979) and community samples (Vernon 1980). The internal consistency of the scale for the present sample was $\alpha=0.89$. In this sample, $35 \%$ of the mothers had symptom levels at or above the cutoff score of 16 , indicating significant risk for depression when their children were in kindergarten.

Maternal Warmth The quality of the parent-child interaction was assessed using a series of parent-child interaction (PCIT) tasks with the following sequence: (1) Child's Game (CG): Child takes the lead in play for $5 \mathrm{~min}$; (2) Parent's Game (PG): Parent takes the lead in play for $5 \mathrm{~min}$; (3) Lego Task (LT): Child tries to reproduce a figure using the Lego blocks for $5 \mathrm{~min}$ with the parent in a teaching role, and (4) Clean-up: Parent gets the child to put away all the toys and Lego blocks.

The Interaction Rating Scale was used to code the observations (IRS; Crnic and Greenberg 1987). One of the two raters was blind to level of maternal depressive symptomatology, while both were blind to level of child externalizing behaviors. Observers completed a total of 24 global ratings characterizing the mother-child interactions along the dimensions of: (1) gratification (degree to which mother and child each enjoyed the interaction), (2) sensitivity (mother's ability to be sensitive and appropriately responsive to her child's cues), (3) responsiveness (degree to which the child attended to and was engaged by the mother's attempts at interaction), (4) control/directiveness (degree to which the mother attempted to run the interaction in her own way), (5) involvement (amount of time the mother and child each spent interacting with the other), (6) clarity of commands (clearness of the mother's commands to her child), (7) follow-through of commands, and, (8) child compliance. Each item was rated on a global 5-point system, with 1 representing a low or negative value and 5 representing a high or positive value; a score of 3 was considered average. Factor analyses revealed that three ratings coalesced in a factor representing maternal warmth-ratings of maternal gratification during the Parent's game (PG) and the Lego Task (LT) and mother's sensitivity during LT, and a composite of these three ratings was used in the present study. Observers were trained on practice videotapes until acceptable levels of reliability were reached. Interobserver agreement on the IRS was assessed on $15 \%$ of the PCIT sessions. Coder reliabilities for the three ratings, utilizing Cohen's kappa for exact agreements, were 0.77 (PG: gratification), 0.69 (LT: gratification), and 0.68 (LT: Sensitivity) (Harnish et al. 1995). Global ratings were chosen as they offer a particularly fruitful and meaningful approach to studying behavioral characteristics in early interaction (Bakeman and Brown 1980). 
Children's Emotion Regulation The Social Health Profile [SHP] Social Competence Scale is a 9-item rating scale assessing social competence (CPPRG 1997). The scale was administered in a face-to-face interview with each classroom teacher along with the 26-item Teacher Observation of Child Adaptation-Revised [TOCA-R] (Werthamer-Larsson et al. 1991). Factor analyses of the SHP Social Competence Scale revealed 2 factors, including a prosocial behavior scale and a separate 4 -item factor measuring emotion regulation. The emotion regulation items included: "controls temper in a disagreement", "appropriate expression of needs/feelings", "thinks before acting" and "can calm down when excited or upset". Teacher ratings used a six-point scale: "Almost Never (0)," "Rarely (1)," "Sometimes (2)," "Often (3)," "Very Often (4)," and "Almost Always (5)." The internal consistency of the 4-item emotion regulation scale was high $(\alpha=0.86)$.

Children's Peer Social Preference During individual interviews, children were shown a roster of their classmates (to assure familiarity) and then asked to nominate children who they "most liked" and those they "least liked". Unlimited nominations were accepted, as these tend to spread more evenly among students in a class than limited nominations (i.e., fewer students receive a raw nomination score of zero). The total least-liked nomination was subtracted from the total most-liked nomination to obtain a measure of social preference. Social preference scores were then standardized within each classroom (Coie et al. 1982).

Family SES and Kindergarten Teacher Rating of Peer Preference Two covariates also were utilized to control for pre-existing risk during kindergarten, family SES and teacher-rated peer preference. The SES variable was reported by the parents during their child's kindergarten year (calculated using the Hollingshead socioeconomic status system; Hollingshead 1975). The child's peer preference during kindergarten was assessed using two teacher rated items from the TOCA-R, which asked teachers to assess how much the child was liked and how much the child was disliked by peers (Werthamer-Larsson et al. 1991). Both items used a six-point response format: "Almost Never (0)," "Rarely (1)," "Sometimes (2)," "Often (3)," "Very Often (4)," and "Almost Always (5)." To form the peer preference rating, the "Disliked" rating was subtracted from the "Liked" rating to create a teacher-rated "proxy" for peer-nominated social preference. Connolly and Doyle (1981) documented that, during the early childhood years, teacher ratings of child peer acceptance have concurrent and predictive validity, correlating with observational assessments of peer relations and peer-nominations.
Analytic Plan

Structural equation modeling with the software Mplus version 4.20 (Muthén and Muthén 1998) was used to build and test a series of latent construct models. Using criteria specified in Holmbeck (1997), we followed a set of steps to test the hypothesized mediational models. We first established the bivariate relations between the mediators (maternal warmth, child emotion regulation), the predictor (maternal depressive symptoms) and the outcome (peer social preference in second grade). Next, to establish mediation, we tested for a significant reduction in the direct effect between the predictor and the outcome, when each mediating variable was included in the model. In a three-variable situation, this is equivalent to testing whether the indirect effect is significantly different from zero (Clogg et al. 1995).

To study this hypothesized mediating influence, we tested a series of structural equation models (see Fig. 1). In all of these models, two kindergarten covariates, teacher-rated peer preference and family SES were added to control for their effects. Comparing Model 1 and 1a, we tested the mediation between maternal depressive symptoms and peer preference by maternal warmth. Similarly, comparing Model 2 and 2a, we tested the mediation between maternal depressive symptoms and peer preference by emotion regulation. In Model 3, we examined the joint mediation effects of maternal warmth and emotion regulation (Fig. 2).

In addition, a multiple group analysis was performed on the data comparing African American and European American families (the few families in the sample that were not European American and not African American were excluded in this analysis). A model with all the structural parameters (direct and indirect effects) constrained to be equal (between the African American and European American groups) was compared to one with all these parameters freely estimated.

\section{Results}

\section{Overview}

We hypothesized that the level of maternal depressive symptomatology during the child's kindergarten year would have a negative impact on the child's peer relations 2 years later. We further proposed that this association would be mediated by both maternal warmth and child emotion regulation measured in grade one. Table 2 shows the zero-order correlations among the observed variables. All the bivariate relations between the predictor (maternal depressive symptoms), mediators (four child emotion regulation items, and three maternal warmth items), and criterion (child peer preference) were statistically significant. 
Fig. 1 Series of SEM models built and tested in the study

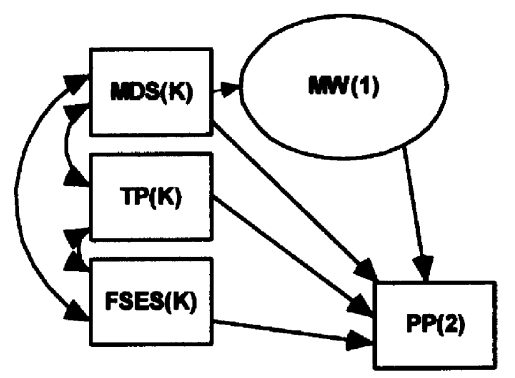

Model 1
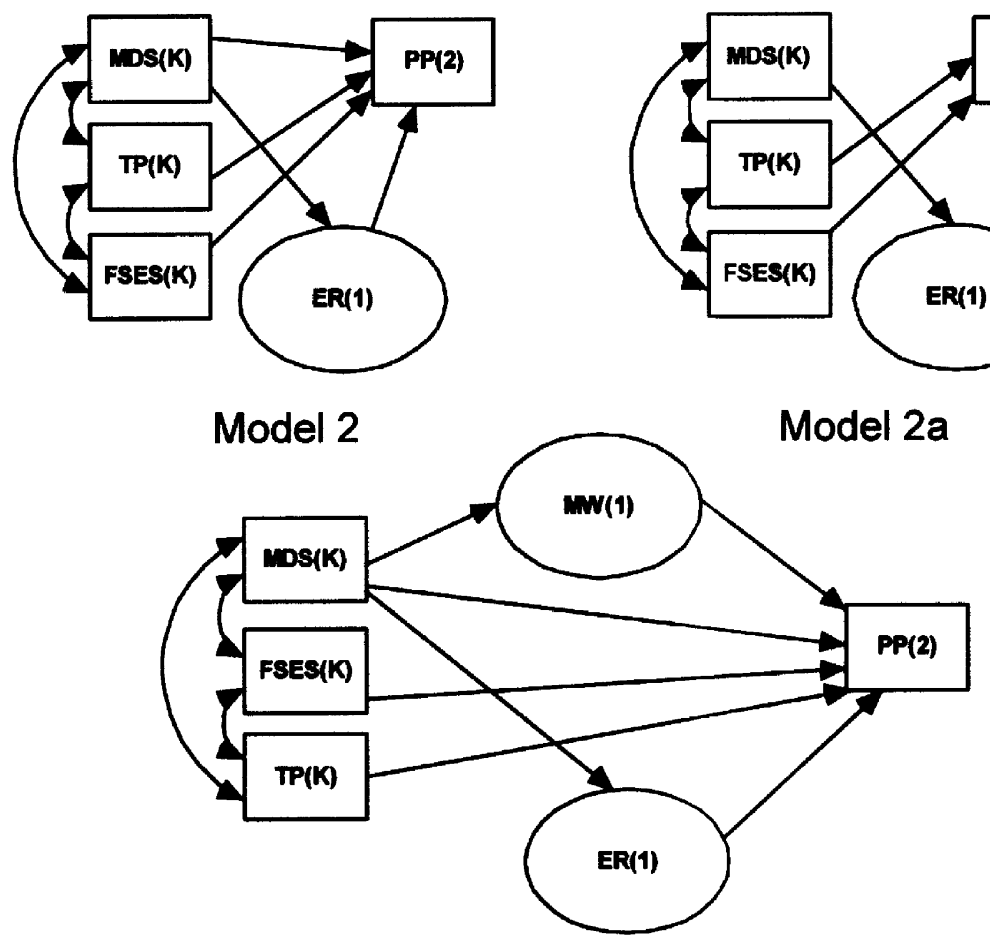

Model 3

MDS (K): Kindergarten maternal depressive symptoms

TP (K): Kindergarten teacher rated social preference

FSES(K): Kindergarten family socioeconomic status

$M W(1)$ : First grade maternal warmth

ER(1): First grade child emotion regulation

PP(2): Second grade peer preference
In the longitudinal follow-up of parents and children, there was a small percentage of non-response on each of the measures, except that for peer social preference the extent of missing data is moderate (maternal depressive symptoms, $2 \%$; maternal warmth, $0.3 \%$; emotion regulation, $7.6 \%$; peer social preference, $23 \%$ ). There is no reason to suspect that the values of the sociometric nominations were associated with whether they are missing or not, hence there is no reason to believe that the "missing at random" assumption does not hold. We also conducted simple analyses to compare study outcomes between the "missing" and the "non-missing" individuals. There was no difference between the two groups on any outcome. Mplus used the full-information maximum likelihood (FIML) method in its parameter estimation. Under the missing-at-random assumption, such a missing data procedure can fully utilize all the available information about the constructs within the data (Collins et al. 2001). 


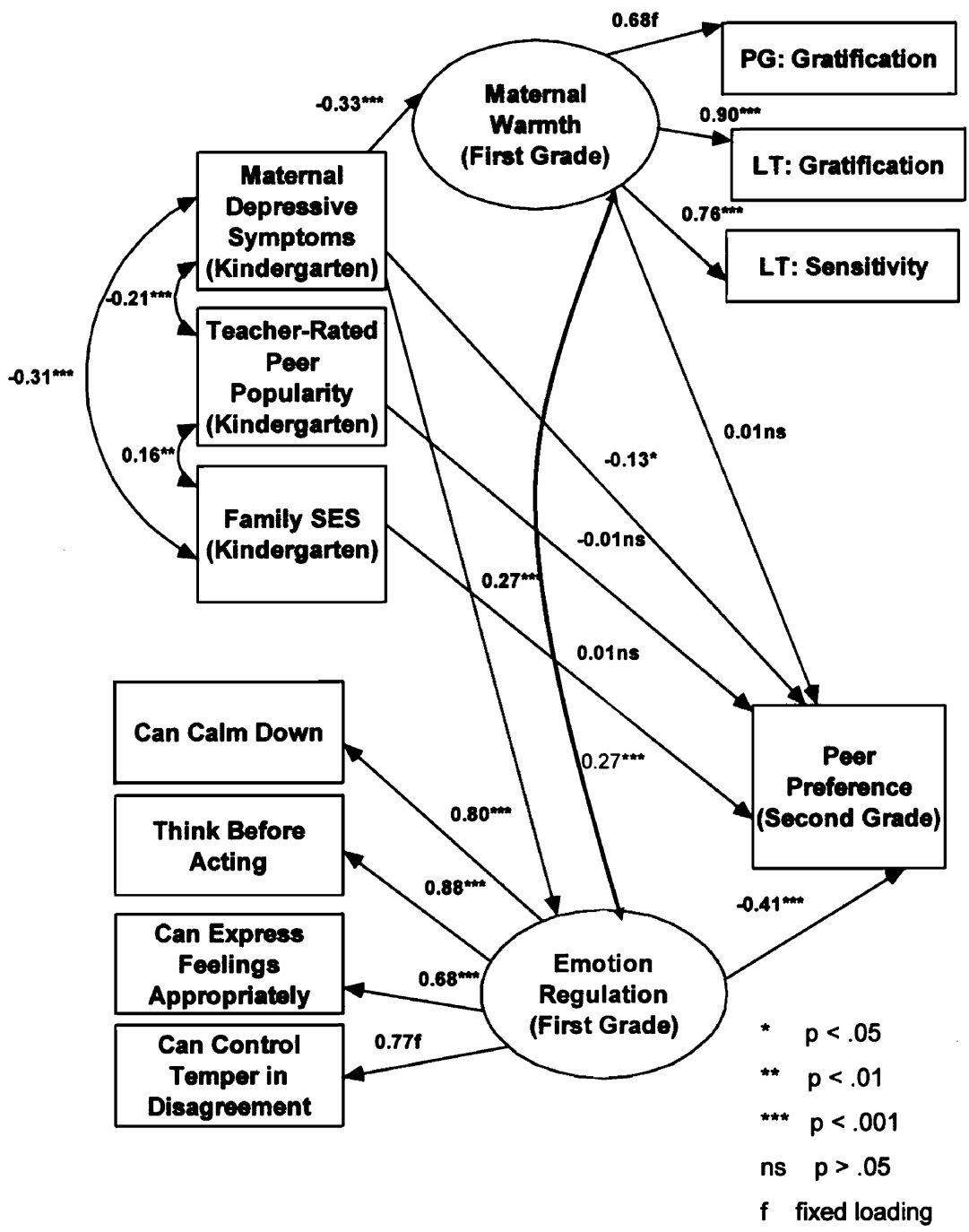

Fig. 2 Joint mediation between maternal depressive symptoms and peer social preference by maternal warmth and child emotion regulation. Path coefficients are standardized and significance levels were determined by critical ratios on unstandardized coefficients

Table 2 Bivariate relationships among the observed variables ${ }^{\text {a }}$

\begin{tabular}{|c|c|c|c|c|c|c|c|c|c|c|c|}
\hline Observed variables ${ }^{\mathrm{b}}$ & 1. & 2. & 3. & 4. & 5. & 6. & 7. & 8. & 9. & 10. & 11. \\
\hline 1. Family SES (K) & - & & & & & & & & & & \\
\hline 2. Control temper (Gr 1) & 0.20 & - & & & & & & & & & \\
\hline 3. Express feelings appropriately (Gr 1 ) & 0.25 & 0.49 & - & & & & & & & & \\
\hline 4. Think before acting ( $\mathrm{Gr} 1)$ & 0.30 & 0.67 & 0.61 & - & & & & & & & \\
\hline 5. Can calm down (Gr 1) & 0.23 & 0.65 & 0.55 & 0.69 & - & & & & & & \\
\hline 6. Maternal depressive symptoms (K) & -0.31 & -0.17 & -0.23 & -0.26 & -0.14 & - & & & & & \\
\hline 7. Parent game: Gratification (Gr 1) & 0.32 & 0.14 & $0.13^{*}$ & 0.21 & 0.19 & -0.21 & - & & & & \\
\hline 8. Lego task: Gratification (Gr 1) & 0.32 & 0.21 & 0.18 & 0.27 & 0.21 & -0.26 & 0.63 & - & & & \\
\hline 9. Lego task: Sensitivity (Gr 1) & 0.33 & 0.26 & 0.26 & 0.33 & 0.24 & -0.37 & 0.47 & 0.68 & - & & \\
\hline 10. Peer social preference ( $\mathrm{Gr} 2$ ) & $0.17 *$ & 0.33 & 0.35 & 0.39 & 0.33 & -0.25 & 0.15 & 0.17 & 0.16 & - & \\
\hline 11. Teacher-rated popularity (K) & 0.16 & 0.33 & 0.33 & 0.35 & 0.34 & -0.20 & $0.02 * *$ & $0.11 *$ & 0.14 & 0.17 & - \\
\hline
\end{tabular}

All correlations among the variables are significant at $p<0.01$ except $* p<0.05$ and $* *$ n.s.

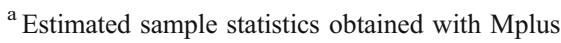

${ }^{\mathrm{b}} \mathrm{K}$ kindergarten; Gr 1 first grade; Gr 2 second grade 
Mediation by Maternal Warmth

There is a possibility that the effect of maternal depressive symptoms on peer relations was mediated directly by the level of maternal warmth in parent child interactions. We tested that hypothesis in Model 1 . The model fit the data reasonably well, with $\chi^{2}(10, N=356)=65.97, p<0.01$, $\mathrm{CFI}=0.88$, RMSEA $=0.12$. Significant indirect effects through maternal warmth were found, standardized indirect effect, $\mathrm{SIE}=-0.04, p<0.05$. We also compared this model with a model in which the direct effect of maternal depressive symptoms on children's social preference was set at zero (Model 1a). There was a significant difference in model fit between Model 1 and Model 1a, $\Delta \chi^{2}(1, N=356)=5.440$, $p<0.05$, indicating that the effect of maternal depressive symptoms on peer social preference was only partially mediated through maternal warmth.

\section{Mediation by Emotion Regulation}

We specified a model (Model 2) in which children's emotion regulation was included as a mediator between maternal depressive symptoms and children's peer social preference. Children's emotion regulation significantly mediated the impact of maternal depressive symptoms effects on children's social preference, $\mathrm{SIE}=-0.11, p<0.01$. We also compared these models with a model (Model 2a) in which the direct effect of maternal depressive symptoms on peer social preference was set at zero. Model 2 fit the data reasonably well, with $\chi^{2}(16, N=356)=84.94, p>0.01, \mathrm{CFI}=0.91$, RMSEA $=0.11$. There was a significant difference in model fit between Model 2 and Model 2a, $\Delta \chi^{2}(1, N=356)=4.62$, $p<0.05$, indicating that the effect of maternal depressive symptoms on peer social preference was only partially mediated through children's emotion regulation.

\section{Joint Mediation by Maternal Warmth and Child Emotion Regulation}

We included both maternal warmth and child emotion regulation in Model 3, and tested the joint meditational effects of the two latent variables. We found that the meditational effect of maternal warmth was reduced to non-significance by the presence of emotion regulation in the model, model fit: $\chi^{2}(37, N=356)=146.35, p<0.001$, $\mathrm{CFI}=0.91, \mathrm{RMSEA}=0.09$; $\mathrm{SIE}=-0.11, p<0.01$. When we compared this model with Model 2 in the previous section, there was not much difference in the size of the total indirect effect (standardized total indirect effect $=-0.11$, $p<0.01)$. Such a result indicates that maternal warmth does not have a unique (meditational) effect above and beyond that of child emotion regulation. On the other hand, there is a moderate correlation between maternal warmth and child emotion regulation, $r=0.27, p<0.01$. In Model 3, the direct effect from maternal depressive symptom to peer social preference remained significant, with a standardized direct effect $[\mathrm{SDE}]=-0.13, p<0.05$. In addition, given that effects in all the models were controlled for family socioeconomic status and child peer popularity in kindergarten, such a result suggests that part of the effect of maternal depressive symptoms on child peer social preference can be explained by the level of family deprivation and deficits in the child's peer acceptance during kindergarten.

\section{Ethnic Differences (African Americans vs. European} Americans)

In the multiple group analysis, there was a significant chi-square difference between the constrained and the freed models $\left(\Delta \chi^{2}(5, N=341)=19.76, p<0.01\right)$, suggesting that some of the direct or indirect effects were different in the African American and European American groups. Specifically, the total mediating effects (maternal warmth and emotion regulation) were larger in the European American group (SIE $=-0.16, p<0.01)$ than the African American group (SIE $=-0.04 \mathrm{~ns}$ ). On the other hand, the remaining direct effect was stronger in the African American group $(\mathrm{SDE}=-0.356, p<0.01)$ than the European American group ( $\mathrm{SDE}=0.09 \mathrm{~ns})$. Such results indicate that the mediation by maternal warmth and emotion regulation existed only among the European American but not African American families. We found two differences contributing to the group differences in mediational models: 1) there was a significant association between maternal depressive symptoms and child emotion regulation among European American families $(r=0.28, p<0.01)$, but not among African American families $(r=0.12$, n.s.), and 2) there was a significant correlation between maternal warmth and child peer relations among European Americans $(r=$ $0.24, p<0.05$, but not African Americans $(r=0.14$, n.s.).

\section{Discussion}

Consistent with findings from other studies on maternal depression and depressive symptoms, the present study demonstrates that mothers' experience of a high level of depressive symptoms during the child's kindergarten year has a lasting negative impact on the child's socio-emotional development and adjustment during the early school years. Children with mothers who had high depressive symptomatology when the child entered school were less accepted by their peers in second grade than children of mothers with lower levels of depressive symptomatology. Since peer social preference was measured in the second grade, a time when 
peer groups and friends are growing in importance to these children, we anticipate that this low peer preference will increase child vulnerability to subsequent maladjustment, adding to the risks evident at school entry. Given that maternal depressive symptoms and peer social preference were measured 2 years apart, it suggests that maternal depressive symptoms has an impact on intervening processes that may magnify the child's risk for social maladjustment.

The process by which maternal depressive symptoms affect children's peer relations is likely to involve multiple mechanisms. Our study focused on two such mediational links-affective quality in mother-child interactions and children's difficulties with emotion regulation. We found that, among European American families, both the affective quality in mother-child interactions and children's difficulties with emotion regulation mediated the link between maternal depressive symptoms and children's peer social preference. However, these mediating relationships did not emerge among African American families.

More specifically, we found that among the European American families, maternal depressive symptoms were associated with child difficulties regulating emotion, and that child emotion regulation substantially mediated the impact of maternal depressive symptoms on children's peer relations. Such findings support Parke's family-peer link model which suggests that children's emotion regulation skills could mediate links between family processes, such as parent-child interaction, and the quality of the child's peer relations (Parke and Ladd 1992). On the other hand, quite unexpectedly, we found that among African American families, the level of maternal depressive symptoms in kindergarten years did predict later child social preference, but it did not predict child emotion regulation difficulties in second grade. Dodge et al. (2005) found that European and African American parents differed in their expressed emotions when they disciplined their children. African American parents were less likely to couple anger with physical discipline. It is possible that the African American parents in our study showed different patterns of expressed emotions towards their children when they experienced high level of depressive symptoms, which might explain the absence of a link between African American mothers' depressive symptomatology and child emotion regulation difficulties.

Maternal warmth also mediated the effect of maternal depressive symptoms on children's peer preference. However, the mediational effect of maternal warmth, though significant, was modest. Such mediation was also only found in the case of European American families. Among African American families, the level of maternal warmth did not predict children's peer preference. Furthermore, we found that the mediational effect of maternal warmth was not a unique effect above and beyond the mediational effect of child emotion regulation. In other words, maternal depression was associated with both low levels of maternal warmth and elevated levels of child emotion dysregulation, but the latter was more proximal to (and accounted for more variance in) the child's social preference, as rated by peers. Related to this finding, Lovejoy and colleagues reviewed research documenting links between maternal depression and different dimensions of parent-child interaction. Among the several components they examined, maternal positive affect during the interactions had the smallest effect size (Lovejoy et al. 2000).

Although the effect of maternal depressive symptoms on child peer preference was mediated both through children's emotion regulation and maternal warmth, the mediation was not complete. In models with both mediators included, there was a significant direct path connecting maternal depressive symptoms and the child's social preference. When we controlled for family SES and children's peer preference during kindergarten year, the direct path was weakened but remained significant. We also note that children's emotion regulation difficulties may have preceded their mother's experience of heightened level of depressive symptoms. We acknowledge the possibility that these early socio-emotional problem behaviors of the child might influence the mothers' mental health and subsequent parenting behaviors or parental warmth. Masten (2001), in her discussion of risk and resilience processes in development, emphasized that "many of these variable-focused models do not accommodate the bidirectional nature of influence in living system" (p. 230). We understand the mediational model used here does not address possible bidirectional effects, in particularly the effects of child behaviors on the quality of parenting.

Of course, our findings do not rule out other possible mediators, such as the effect of social cognition. Children of depressed mothers may develop negative attributions or attitudes about interpersonal relationships that could affect their actual interactions with peers (Garber and Martin 2002). Second, maternal depressive symptoms maybe associated with other familial factors that can have an impact on children's social behaviors, such as the quality of parents' marital relationship, existence of other stressors in the family, and the degree of social support from other family members (Cummings et al. 2005; Davies and Cummings 1994; Hammen 2002). Finally, our study cannot rule out the possibility of genetic influence. It is likely that there are common characteristics shared by mothers at high risk for depression and their children, especially those involving negative affectivity or self regulatory abilities, which might affect the quality of peer relationships (Silberg and Rutter 2002).

Several limitations of the present research should be kept in mind. First, although there was a significant relationship between maternal depressive symptoms and 
other constructs, the effects were only modest. The relatively weak relationship between mother and child outcomes indicates that the relationship between maternal depressive symptoms and child socio-emotional behaviors maybe moderated by other personal and contextual factors. The use of the CES-D and a community sample precludes the direct comparison of our results with those studies that have used diagnostic measures of depression and clinical samples of depressed mothers. Third, there was a modest rate of missing data for peer social preference data. Although we have applied the latest missing data procedure (in Mplus) to deal with the missingness, we expect that our parameter estimates for this part of the model maybe somewhat inefficient.

In summary, this study shows that young children of mothers who experienced a high level of depressive symptoms are at risk for poor peer relations at the time they enter school. This risk might be partially mediated by both these mothers' lack of warmth and their children's low level of emotion regulation skills. Such a result matches with our expectation that when mothers experience a high level of depressive symptoms, a lot of which is related to mothers' own emotion dysregulation, which can affect offspring's social and emotional functioning. However, different kinds of mediating processes might be in operation for families of different ethnic origins. While we showed that the two mediational links were in operation among European American families, such links were not active among African American families. Thus, alternative mediating mechanisms are working among African American families. Further research examining possible culture-specific processes are needed to extend our understanding of the important influence of ethnicity on the transmission of risk within families with parents who show elevated depressive symptoms.

Open Access This article is distributed under the terms of the Creative Commons Attribution Noncommercial License which permits any noncommercial use, distribution, and reproduction in any medium, provided the original author(s) and source are credited.

\section{References}

Bakeman, R., \& Brown, J. V. (1980). Early interaction: consequences for social and mental development at three years. Child Development, 51, 437-447.

Bierman, K. (2004). Peer rejection: Developmental processes and intervention strategies. New York: Guilford Press.

Blandon, A. Y., Calkins, S. D., Keane, S. P., \& O’Brien, M. (2008). Individual differences in trajectories of emotion relation processes: the effects of maternal depressive symptomatology and children's physiological regulation. Developmental Psychology, 44, 11101123.
Burt, K. B., Van Dulmen, M. H. M., Carlivati, J., Egeland, B., Sroufe, L. A., Forman, D. R., et al. (2005). Mediating links between maternal depression and offspring psychopathology: the importance of independent data. Journal of Child Psychology and Psychiatry, $46,490-499$.

Caughy, M. O., Huang, K.-Y., \& Lima, J. (2009). Patterns of conflict interaction in mother-toddler dyads: differences between depressed mothers. Journal of Child and Family Studies, 18, $10-20$.

Cillessen, A. H. N., \& Mayeux, L. (2004). Sociometric status and peer group behavior: previous findings and current directions. In J. B. Kupersmidt \& K. A. Dodge (Eds.), Children's peer relations: From development to intervention (pp. 3-20). Washington: American Psychological Association.

Clogg, C. C., Petkova, E., \& Haritou, A. (1995). Symposium on applied regression: statistical methods for comparing regression coefficients between models. The American Journal of Sociology, 100, 1261-1293.

Coie, J. D., Dodge, K. A., \& Coppotelli, H. (1982). Dimensions and types of social status: a cross-age perspective. Developmental Psychology, 18, 557-570.

Collins, L. M., Schafer, J. L., \& Kam, C.-M. (2001). A comparison of inclusive and restrictive strategies in modern missing-data procedures. Psychological Methods, 6, 330-351.

Conduct Problems Prevention Research Group. (1992). A developmental and clinical model for the prevention of conduct disorders: the fast track program. Development and Psychopathology, 4, 509527.

Conduct Problems Prevention Research Group (1997). Social Health Profile and TOCA-R. Unpublished technical report.

Connolly, J., \& Doyle, A. B. (1981). Assessment of social competence in preschoolers: teacher versus peers. Developmental Psychology, $17,454-462$.

Contreras, J. M., \& Kerns, K. A. (2000). Emotion regulation processes: Explaining links between parent-child attachment and peer relationships. In K. A. Kerns, J. M. Contreras, \& A. M. Neal-Barnett (Eds.), Family and peers: Linking two social worlds (pp. 1-26). Westport, Connecticut: Praeger Publishers.

Craig, T. J., \& Van Natta, P. A. (1979). Influence of demographic characteristics on two measures of depressive symptoms. Archive of General Psychiatry, 36, 149-154.

Crick, N. R., \& Dodge, K. A. (1994). A review and reformulation of social information processing in children's social adjustment. Psychological Bulletin, 115, 74-101.

Crnic, K., \& Greenberg, M. T. (1987). Transactional relationships between perceived family style, risk status, and mother-child interactions in two year olds. Journal of Pediatric Psychology, $12,343-362$.

Cummings, E. M., Keller, P. S., \& Davies, P. T. (2005). Towards a family process model of maternal and paternal depressive symptoms: exploring multiple relations with child and family functioning. Journal of Child Psychology and Psychiatry, 46, 479-489.

Davies, P., \& Cummings, E. M. (1994). Marital conflict and child adjustment: an emotional security hypothesis. Psychological Bulletin, 116, 387-411.

Deater-Deckard, K., Lansford, J. E., Dodge, K. A., Pettit, G. S., \& Bates, J. E. (2003). The development of attitudes about physical punishment: an 8-year longitudinal study. Journal of Family Psychology, 17, 351-360.

Denham, S. A., Zoller, D., \& Couchoud, E. A. (1994). Socialization of preschoolers' emotion understanding. Developmental Psychology, 30, 928-936.

Denham, S. A., Mitchell-Copeland, J., Strandberg, K., Auerbach, S., \& Blair, K. (1997). Parental contributions to preschoolers' emotional competence: direct and indirect effects. Motivation and Emotion, 21, 65-86. 
Denham, S. A., Blair, K. A., DeMulder, E., Levitas, J., Sawyer, K., Auerbach-Major, S., et al. (2003). Preschool emotional competence: pathway to social competence. Child Development, 74, 238-256.

Dodge, K. A., McLoyd, V. C., \& Lansford, J. E. (2005). The cultural context of physically disciplining children. In V. C. McLoyd, N. E. Hill, \& K. A. Dodge (Eds.), Emerging issues in African American family life: context, adaptation, and policy (pp. 245263). New York: Guilford Press.

Downey, G., \& Coyne, J. C. (1990). Children of depressed parents: an integrative review. Psychological Bulletin, 108, 50-76.

Eisenberg, N., Fabes, R. A., Bernzweig, J., Karbon, M., Poulin, R., \& Hanish, L. (1993). The relations of emotionality and regulation to preschoolers' social skills and sociometric status. Child Development, 64, 1418-1438.

Eisenberg, N., Cumberland, A., \& Spinrad, T. L. (1998). Parental socialization of emotion. Psychological Inquiry, 9, 241-273.

Eisenberg, N., Cumberland, A., Spinrad, T. L., Fabes, R. A., Shepard, S. A., Reiser, M., et al. (2001). The relations of regulation and emotionality to children's externalizing and internalizing problem behavior. Child Development, 72, 1112-34.

Emery, R. E., Weintraub, S., \& Neale, J. (1982). Effects of marital discord on the school behavior of children of schizophrenic, affective disordered, and normal parents. Journal of Abnormal Child Psychology, 16, 215-225.

Field, T., Healy, B., Goldstein, S., \& Guthertz, M. (1990). Behaviorstate matching and synchrony in mother-infant interactions of nondepressed versus depressed dyads. Developmental Psychology, 26, 7-14.

Garber, J., \& Martin, N. C. (2002). Negative cognitions in offspring of depressed parents: Mechanisms of risk. In S. H. Goodman \& I. Gotlib (Eds.), Children of depressed parents: Mechanisms of risk and implications for treatment (pp. 121-154). Washington: American Psychological Association.

Gladstone, T. R., \& Kaslow, N. J. (1995). Depression and attributions in children and adolescents: a meta-analytic review. Journal of Abnormal Child Psychology, 23, 596-606.

Goodman, S. H. (2007). Depression in mothers. Annual Review of Clinical Psychology, 3, 107-135.

Goodman, S. H., \& Gotlib, I. H. (1999). Risk for psychopathology in the children of depressed mothers: a developmental model for understanding mechanisms of transmission. Psychological Review, $106,458-490$

Goodman, S. H., Brogan, D. R., Lynch, M. E., \& Fielding, B. (1993). Social and emotional competence in children of depressed mothers. Child Development, 64, 513-531.

Gottman, J. M., \& Katz, L. F. (1989). Effects of marital discord on young children's peer interaction and health. Developmental Psychology, 25, 373-381.

Gottman, J. M., Katz, L. F., \& Hooven, C. (1996). Parental metaemotion philosophy and the emotional life of families: theoretical models and preliminary data. Journal of Family Psychology, 10, $243-268$

Halberstadt, A. G., Denham, S. A., \& Dunsmore, J. C. (2001). Affective social competence. Social Development, 10, 79-119.

Hammen, C. L. (2002). Context of stress in families of children with depressed parents. In S. H. Goodman \& I. Gotlieb (Eds.), Children of depressed parents: Mechanisms of risk and implications for treatment (pp. 175-202). Washington: American Psychological Association.

Harnish, J. D., Dodge, K. A., Valente, E., \& Conduct Problems Prevention Research Group. (1995). Mother-child interaction quality as a partial mediator of the roles of maternal depressive symptomatology and socioeconomic status in the development of child behavior problems. Child Development, $66,739-753$
Hart, C. H., Ladd, G. W., \& Burleson, B. R. (1990). Children's expectations of the outcomes of social strategies: relations with sociometric status and maternal disciplinary styles. Child Development, 61, 127-137.

Hollingshead, A. B. (1975). Four-factor index of social status. Unpublished manuscript. Yale University, New Haven, CT.

Holmbeck, G. (1997). Toward terminological, conceptual, and statistical clarity in the study of mediators and moderators: examples from the child-clinical and pediatric psychology literatures. Journal of Consulting and Clinical Psychology, 65, 590-610.

Huang, K. Y., Teti, D. M., Caughy, M. O., Feldstein, S., \& Genevro, J. (2007). Mother-child conflict interaction in the toddler years: behavior patterns and correlates. Journal of Child and Family Studies, 16, 219-241.

Hubbard, J. A. (2001). Emotion expression processes in children's peer interaction: the role of peer rejection, aggression, and gender. Child Development, 72, 1426-1438.

Hubbard, J. A., \& Coie, J. D. (1994). Emotional correlates of social competence in children's peer relationships. Merrill-Palmer Quarterly. Special Issue: Children's emotions and social competence, 40, 1-20.

Hubbard, J. A., \& Dearing, K. F. (2004). Children's understanding and regulation of emotion in the context of their peer relations. In J. B. Kupersmidt \& K. A. Dodge (Eds.), Children's peer relations: from development to intervention (pp. 81-100). Washington: American Psychological Association.

Hwa-Froelich, D. A., Cook, C. A. L., \& Flick, L. H. (2008). Maternal sensitivity and communication styles: mothers with depression. Journal of Early Intervention, 31, 44-66.

Lemerise, E. A., \& Arsenio, W. F. (2000). An integrated model of emotion processes and cognition in social information processing. Child Development, 71, 107-118.

Lochman, J., \& Conduct Problems Prevention Research Group. (1995). Screening of child behavior problems for prevention programs at school entry. Journal of Consulting and Clinical Psychology, 63, 549-559.

Lovejoy, M. C., Graczyk, P. A., O'Hare, E., \& Neuman, G. (2000). Maternal depression and parenting behavior: a meta-analytic review. Clinical Psychology Review, 20, 561-592.

Luoma, I., Tamminen, T., Kaukonen, P., Laippala, P., Puura, K., Salmelin, R., et al. (2001). Longitudinal study of maternal depressive symptoms and child well-being. Journal of the American Academy of Child and Adolescent Psychiatry, 40, $1367-1374$.

Masten, A. S. (2001). Ordinary magic: resilience processes in development. The American Psychologist, 56, 227-238.

Muthén, L. K., \& Muthén, B. O. (1998-2006). Mplus user's guide, 4th edn. Los Angeles, CA: Muthén \& Muthén

Parke, R. D., \& Ladd, G. W. (1992). Family-peer relationships: Modes of linkage. Hillsdale: Lawrence Erlbaum Associates, Inc.

Parke, R. D., Burks, V., Carson, J., Neville, B., \& Boyum, L. (1994). Family -peer relationships: A tripartite model. In R. D. Parke \& S. Kellam (Eds.), Advances in family research Vol. 4: Family relationships with other social systems (pp. 115-145). Hillsdale: Erlbaum.

Parker, J. G., Rubin, K. H., Erath, S. A., Wojslawowicz, J. C., \& Buskirk, A. A. (2006). Peer relationships, child development, and adjustment: A developmental psychopathology perspective. In D. Cicchetti \& D. Cohen (Eds.), Developmental psychopathology: Vol. 1: Theory and method (2nd ed., pp. 419-493). New York: Wiley.

Petterson, S. M., \& Albers, A. B. (2001). Effects of poverty and maternal depression on early child development. Child Development, $72,1794-1813$. 
Putallaz, M. (1987). Maternal behavior and children's sociometric status. Child Development, 58, 324-340.

Putallaz, M., \& Heflin, A. H. (1990). Parent-child interaction. In S. R. Asher \& J. D. Coie (Eds.), Peer rejection in childhood (pp. 189216). New York: Cambridge University Press.

Radloff, L. S. (1977). The CES-D scale: a self-report depression scale for research in the general population. Applied Psychological Measurement, 3, 385-401.

Silberg, J., \& Rutter, M. (2002). Nature-nurture interplay in the risks associated with parental depression. In S. H. Goodman \& I. Gotlib (Eds.), Children of depressed parents: Mechanisms of risk and implications for treatment (pp. 13-36). Washington: American Psychological Association.

Spinrad, T. L., Eisenberg, N., Cumberland, A., Fabes, R. A., Valiente, C., Shepard, S. A., et al. (2006). Relation of emotion-related regulation to children's social competence: a longitudinal study. Emotion, 6, 498-510.

Vernon, S. (1980). An investigation of the reliability and validity of the center for epidemiologic studies depression scale in three ethnic groups. Unpublished doctoral thesis, University of Texas.

Waylen, A., \& Stewart-Brown, S. (2010). Factors influencing parenting in early childhood: a prospective longitudinal study focusing on change. Child: Care, Health and Development, 36 , 198-207.

Webster-Stratton, C., \& Hammond, M. (1988). Maternal depression and its relationship to life stress, perceptions of child behavior problems, parenting behaviors, and child conduct problems. Journal of Abnormal Child Psychology, 16, 299-315.

Weissman, M. M., Prusoff, B., Gammon, G. D., Merikangagas, K. R., Leckman, J. F., \& Kidd, K. K. (1984). Psychopathology in the children (ages 6-18) of depressed and normal parents. Journal of the American Academy of Child and Adolescent Psychiatry, 23, 78-84.

Werthamer-Larsson, L., Kellam, S. G., \& Wheeler, L. (1991). Effect of first-grade classroom environment on child shy behavior, aggressive behavior, and concentration problems. American Journal of Community Psychology, 19, 585-602.

Wright, C. A., George, T. P., Burke, R., Gelfand, D. M., \& Teti, D. M. (2000). Early maternal depression and children's adjustment to school. Child Study Journal, 30, 153-168.

Zahn-Waxler, C., Denham, S., Iannotti, R., \& Cummings, E. M. (1992). Peer relations in children with a depressed caregiver. In R. D. Parke \& G. W. Ladd (Eds.), Family-peer relationships: Modes of linkage (pp. 317-344). Hillsdale: Erlbaum. 